Objectives Quality pathology assessment and reporting of gynecological cancers remains a significant challenge worldwide. Since 2019, the International Gynecological Cancer Society has been offering pathology support to underserved countries through monthly multidisciplinary conferences involving local and expert pathologists. We describe the format of this intervention.

Methods An expert pathologist joins conferences at 3-5 sites from underserved countries and discusses the clinical management of challenging cases selected by local gynecologic oncologists. Local and expert gynecologic surgical oncologists participate at each meeting, with occasional participation from radiation oncologists. Local pathologists from two sites consistently participate in these conferences; only these two sites submit pathology images and reports for review by an expert pathology consultant, who provides feedback on the accuracy of the diagnosis and the completeness of the pathology report. Other sites provide only a summary of the pathology diagnosis for discussion. All discussed cases are recorded in an Excel spreadsheet and include details on the management recommendations and the diagnostic pathology reports.

Results A pathology report remains a major challenge for local pathologists. The details important for tumor staging and management are often scarce or not present. The sites with involved local pathologists are starting to use International Collaboration on Cancer Reporting (ICCR) checklist for completeness of the report.

Conclusions Successful collaboration between local pathologists and international consultants is the first step towards improving the quality of pathology at many sites. The involvement of the local pathologists in the multi-disciplinary conferences and the collaboration with expert pathology consultants is crucial for the advancement of diagnostic oncology in underserved countries.

\section{EPV160/\#618 GLOBAL ASSESSMENT OF GUIDELINES FOR BRCA1/2 GENETIC TESTING: CALL TO ACTION IN HEALTH EQUITY FOR WOMEN AND FAMILIES AT RISK FOR HEREDITARY OVARIAN CANCER}

${ }^{1}$ BN Hughes*, ${ }^{2} \mathrm{JA}$ Rauh-Hain, ${ }^{1} \mathrm{TJ}$ Herzog, ${ }^{3} \mathrm{~S}$ Cummings, ${ }^{3} \mathrm{OL}$ O'Hanlon, ${ }^{3} \mathrm{D}$ Morah. ${ }^{1}$ University of Cincinnati, Cancer Center, Cincinnati, USA; ${ }^{2}$ University of Texas MD Anderson Cancer Center, Gynecologic Oncology, Houston, USA; ${ }^{3}$ Myriad Genetics, Salt Lake City, USA

\subsection{6/ijgc-2021-IGCS.230}

Objectives Personal and familial knowledge of genetic predispositions, especially BRCA1/2 deleterious mutations, have increasing implications in cancer prevention and outcomes. [1, 2] Lack of genetic testing is a barrier to global health equity. We explored the current state of genetic testing throughout the world and assessed regional variabilities.

Methods Guidelines for BRCA testing were found in publications, position papers, and online documents that outline testing criteria through a non-systematic literature review conducted by two certified cancer genetic counselors. Six categories for testing BRCA were created to capture the wide breadth of testing standards worldwide (table 1). [3-16]

Results Worldwide variability in BRCA testing persists even in regions with codified guidelines. Even regions with the economic structure to support widespread testing and clearly defined guidelines, (i.e. United States and United Kingdom) are undertesting for BRCA. Accessibility of these guidelines alone poses a regional difficulty not only for public
Abstract EPV160/\#618 Table 1 Categorical description of BRCA testing guidelines and regions which meet the criteria

\begin{tabular}{|c|c|c|c|}
\hline Category & Description & Region [3-16] & \\
\hline 1 & $\begin{array}{l}\text { Places/regions that have } \\
\text { formalized testing criteria - (i.e. } \\
\text { US with NCCN, ACOG, } \\
\text { USPSTF; UK with NICE) }\end{array}$ & $\begin{array}{l}\text { United States of America } \\
\text { United Kingdom } \\
\text { Australia } \\
\text { China } \\
\text { Canada } \\
\text { Wales/Australia } \\
\text { India } \\
\text { France } \\
\text { Netherlands }\end{array}$ & $\begin{array}{l}\text { Germany } \\
\text { South America } \\
\text { Mexico } \\
\text { Spain } \\
\text { Malasia } \\
\text { Norway } \\
\text { Colombia } \\
\text { Brazil }\end{array}$ \\
\hline 2 & $\begin{array}{l}\text { Places/regions that only do testing } \\
\text { on a research/clinical - no } \\
\text { defined national or professional } \\
\text { criteria }\end{array}$ & $\begin{array}{l}\text { Korea } \\
\text { Nigeria } \\
\text { Nepal } \\
\text { Saudi Arabia } \\
\text { Pakistan } \\
\text { Columbia }\end{array}$ & $\begin{array}{l}\text { Japan } \\
\text { Northern Africa } \\
\text { (excluding Libya } \\
\text { South Africa) }\end{array}$ \\
\hline 3 & $\begin{array}{l}\text { Places/regions where there is no } \\
\text { indication testing is done }\end{array}$ & \multicolumn{2}{|l|}{$\begin{array}{l}\text { Russia } \\
\text { Qatar }\end{array}$} \\
\hline 4 & $\begin{array}{l}\text { Places/regions that are exploring } \\
\text { population-based testing }\end{array}$ & \multicolumn{2}{|l|}{$\begin{array}{l}\text { United States of America } \\
\text { Canada } \\
\text { Australia } \\
\text { Srael }\end{array}$} \\
\hline 5 & $\begin{array}{l}\text { Inconclusive data / know doing } \\
\text { research but can't find criteria }\end{array}$ & \multicolumn{2}{|l|}{$\begin{array}{l}\text { Philippines } \\
\text { Finland } \\
\text { Sweden }\end{array}$} \\
\hline
\end{tabular}

knowledge and awareness, but uniform practice among healthcare providers.

Conclusions Global assessment of BRCA-directed guidelines are tremendously variable; therefore, formalized global guidelines are needed to expand access to testing, thereby improve health equity and patient outcomes. Lack of implementation even in Category-1 regions, highlights the need for greater awareness of guideline recommended care, and additional strategies to ensure optimized guideline adherence coverage.

\section{EPV161/\#265 CHALLENGES IN HISTOPATHOLOGICAL DIAGNOSIS AND CLASSIFICATION OF PRIMARY UTERINE SARCOMAS IN A REGIONAL TERTIARY ONCOLOGY CENTRE OVER A 5 YEAR PERIOD}

E Papadakou*, V Elliot. University Hospital Southampton, Pathology Department, Southampton, UK

\subsection{6/ijgc-2021-IGCS.231}

Objectives We aimed to determine clinicopathological characteristics of uterine sarcomas and compare the initial histological diagnosis at a tertiary oncology centre with the expert opinion from a specialist sarcoma unit.

Methods The histopathology electronic data base was searched using the key words 'Uterine' and 'Sarcoma'. All clinical and histological characteristics were collected retrospectively. The expert pathology diagnosis was also collected, where available and compared with the initial opinion offered by our department.

Results From January 2015 to January 2020 thirty seven patients were identified. Their median age was 61 years (2382). Eighteen patients $(48.6 \%)$ had Leiomyosarcoma, 6 (16.2\%) Low grade endometrial stromal sarcoma, 5 (13.5\%) High grade endometrial stromal sarcoma, 3 (8.1\%) Undifferentiated uterine sarcoma, 3 (8.1\%) Rhabdomyosarcoma and 2 Adenosarcoma (5.4\%). In 19 (51.3\%) cases a second expert review had been sought from a sarcoma unit. There was diagnostic agreement in almost $80 \%$ of the cases with the HGESS being the most challenging. $81 \%$ of patients underwent surgery and $7(18.9 \%)$ received chemotherapy or radiotherapy. 30 
$(81 \%)$ patients had early stage disease. Fifteen patients $(40.5 \%)$ had a recurrence, with the commonest sites being the pelvis and distant lung metastasis. Seventeen of the patients have died (46\%).

Conclusions In our series there was good correlation between the initial diagnosis and the expert opinion. However, in certain tumour types, specialist review was particularly beneficial in reaching the final diagnosis. This may reflect the enhanced availability of molecular testing at centralised specialist centres. The prognosis is generally unfavourable even in early stage disease.

\section{EPV162/\#343 EDUCATIONAL VALUE OF USING CASE-BASED, RECORDED, OPEN-ACCESS VIDEOMICROSCOPY IN GYNECOLOGIC PATHOLOGY}

L Hassell*. University of Oklahoma Health Sciences Center, Pathology, Oklahoma City, USA Minor Outlying Islands

\subsection{6/ijgc-2021-IGCS.232}

Objectives The COVID-19 pandemic mandated shifting teaching methods to socially distanced modalities. We took the opportunity to create enduring video-microscopy materials of several types using digital slides and offer them via social media to our trainees. Most of the videos also provided links to digital slides for follow-up self-study. After 13 months of providing content, we assess the reach of the effort, and collate responses.

Methods Whole slide images from personal, institutional and public libraries on PathPresenter were used to prepare video presentations, augmented by presentation slides uploaded into the presentation module of the Digital Anatomic Pathology Academy. Video recordings of the presentation were then uploaded to YouTube and the links shared via social media channels (Facebook and Twitter) and email notice to trainees. YouTube channel analytics provided total views, geographic reach of audience and retention times for each video, as well as comments and reactions. Facebook audience reach was also available for videos posted to groups.

Results A total of 89 gynecologic pathology videos were produced and posted, generating a total of 16,718 views, 180 comments, 792 likes and an unknown number of shares. Average audience reach of Facebook-posted videos was 1,500 using a single niche site directed at developing world pathologists. Survey data from group users indicated that most had directly viewed the digital slides.

Conclusions Teaching videos are eagerly received by trainees and practitioners, offer access to unique and common cases, and assist pathology and non-pathology trainees. Patients also gain from the content. Linkage with digital slides is a valued enhancement.

\section{EPV163/\#402 IMPACT OF LYMPH NODE STAGING IN EARLY- STAGE OVARIAN CARCINOMA}

${ }^{1} \mathrm{~F}$ Teixeira*, ${ }^{1} \mathrm{~V}$ De Castro, ${ }^{1} \mathrm{C}$ Faloppa, ${ }^{1} \mathrm{~L}$ Kumagai, ${ }^{1} \mathrm{H}$ Mantoan, ${ }^{1} \mathrm{~L}$ Badiglian-Filho, ${ }^{1} \mathrm{~A}$ Menezes, ${ }^{1} \mathrm{~B}$ Goncalves, ${ }^{2} \mathrm{~A}$ Guimaraes, ${ }^{2} \mathrm{~A}$ Da Costa, ${ }^{1} \mathrm{G}$ Baiocchi. ${ }^{1} \mathrm{AC}$ Camargo Cancer Center, Gynecologic Oncology, Sao Paulo, Brazil; ${ }^{2} A C$ Camargo Cancer Center, Medical Oncology, São Paulo, Brazil

10.1136/ijgc-2021-IGCS.233
Objectives Our aim was to analyze the prevalence of positive lymph node in presumed early-stage ovarian carcinoma (OC) after systematic lymph node dissection (LND) and the impact in adjuvant chemotherapy.

Methods We evaluated a series of 765 patients with OC who underwent surgical treatment from January 2007 to December 2019. Patients with peritoneal disease and incomplete surgical staging were excluded. All cases had systematic pelvic and paraaortic LND up to the renal vessels. After patient referral to our center, a second surgery for staging was done in $37.8 \%$ of cases.

Results A total of 142 cases were ultimately included. The median pelvic and paraaortic lymph nodes (LN) dissected were 30 (range,6-81) and 21 (range,3-86), respectively. Stage shifts after LND and LN metastasis occurred in $8.4 \%$ of cases (12/142) - high-grade serous, $11.9 \%$ (5/42); clear cell, $16.6 \%$ (5/30); endometrioid, 5.1\% (2/39); mixed, 0\% (0/13); and mucinous, $0 \%$ (0/19). Notably, we found clinically suspicious LN (imaging or intraoperative) in 50\% of the metastatic LN. Median hospital stay length was 6 days (range,2-33) and $3.6 \%$ had grade $\geq 3$ complications. Moreover, 110 (77.6\%) patients underwent adjuvant chemotherapy and all cases had indication due to histologic type regardless the result of $\mathrm{LN}$ staging. After a median follow-up of 50.7months (range,1206) we noted 27 (18.9\%) recurrences, and the 5-years recurrence free and overall survival were $92.5 \%$ and $98.1 \%$, respectively.

Conclusions We found a relatively low rate of lymph node positivity and half of positive cases had clinically suspicious LN. The LN status did not impact the indication of adjuvant chemotherapy.

\section{EPV164/\#428 CLINICAL SIGNIFICANCE OF MR IMAGING IN THE JUDGMENT OF LYMPH NODE METASTASIS IN GYNECOLOGICAL MALIGNANT TUMORS}

J Wang*, Y Tang. Chongqing University Cancer Hospital, The Gynecologic Oncology Center Chongqing, China

\subsection{6/ijgc-2021-IGCS.234}

Objectives The lymph node metastasis is closely related to tumor prognosis, and the formulation of postoperative treatment for gynecological malignant tumors. The purpose of this paper is to investigate the clinical value of magnetic resonance imaging in lymph node metastasis of gynecological malignant tumors.

Methods 208 patients undergoing pelvic lymph node and para-aortic lymph node dissection in the Department of Gynecology Chongqing University Cancer Hospital from January 2014 to June 2018 were analyzed retrospectively. SAS9.2 software was used for statistical analysis.

Results The pathological diagnosis in 208 patients showed that 63 patients has pelvic lymph node metastasis, Transfer rate is $30.29 \%$. The sensitivity of MRI to pelvic lymph node transfer is $41.27 \%$.Specificity is $92.41 \%$, Positive forecast value is $70.27 \%$.Negative forecast value is $78.36 \%$.Two-related sample rate test (McNemar test), McNmar Statistics:14.08, $\mathrm{P}=0.0002$, $\mathrm{Kappa}=0.38,95 \% \mathrm{CI}(0.24,0.52)$, The detection rates of the two detection methods differ significantly.37 patients with abdominal aortic lymph node metastasis, Transfer rate is $17.79 \%$.Sensitivity is $29.73 \%$. Specificity is $98.25 \%$.Positive forecast value is $78.57 \%$, Negative forecast value of $86.60 \%$. 